\title{
THE EFFECTS OF VENOUS CONGESTION OF THE LIMBS AND PHLEBOTOMY UPON RENAL CLEARANCES AND THE EXCRETION OF WATER \\ AND SALT. II. STUDIES IN PATIENTS WITH CONGESTIVE FAILURE ${ }^{1}$
}

\author{
By WALTER E. JUDSON, J. D. HATCHER,2 WILLIAM HOLLANDER, MEYER \\ H. HALPERIN, AND ROBERT W. WILKINS
}

\author{
(From the Evans Memorial, Massachusetts Memorial Hospitals, and the Department of \\ Medicine, Boston University School of Medicine, Boston, Mass.)
}

(Submitted for publication April 22, 1955; accepted July 6, 1955)

A previous report from this laboratory (1) has shown that venous congestion of the limbs in normal subjects and in hypertensive patients before and after splanchnicectomy causes a decrease in urine flow and sodium excretion. In the present study these observations were extended to include also the renal functional effects of phlebotomy (as well as of venous congestion) in patients with congestive heart failure. In addition, cardiohemodynamic measurements were made simultaneously in a majority of patients in order to determine whether changes of cardiac output, or blood pressure in the pulmonary artery, or right ventricle are consistently related to the renal excretory responses. The details of the cardiohemodynamic studies have been presented in a separate communication (2).

\section{PATIENTS}

All of the twenty-one patients were considered to be in congestive heart failure on the basis of their clinical cardiovascular symptoms and signs and their abnormal hemodynamic responses to exercise. Seven patients had rheumatic heart disease, six arteriosclerotic heart disease, three hypertensive cardiovascular disease, and one luetic heart disease. Two patients (W. D., W. H.) had cor pulmonale with very severe congestive failure. Two other patients (D. K., C. Di.) had elevated pulmonary arterial pressures without electrocardiographic or roentgenographic evidence of right ventricular enlargement, but the hemodynamic measurements of right ventricular filling pressure during exercise indicated mild right ventricular failure. All of the patients, except D. K., H. A., and R. H., had moderate to severe peripheral edema during the study. All of the patients were on

1 This investigation was supported in part by a grant from the National Heart Institute of the National Institutes of Health, U. S. P. H. S.

2 Present address : Queen's University, Kingston, Ontario, Canada. maintenance oral digitalis therapy, but none of them had received mercurial diuretics for at least one week prior to the procedure. Although some restriction of the amount of salt in the diet had been prescribed, most of the patients had an intake of more than $3 \mathrm{gm}$. of sodium chloride a day.

\section{PROCEDURE AND METHODS}

The patients were studied in the post-absorptive state without sedative pre-medication. An indwelling catheter was placed in the urinary bladder. After standard priming doses, a sustaining infusion containing inulin (3.3 per cent) and para-aminohippurate ( 0.5 per cent) in 3.5 per cent glucose and water was started and given at the rate of $1.2 \mathrm{ml}$. per minute by means of a calibrated drip. A double lumen intracardiac catheter was inserted into the right heart so that simultaneous records of the pulmonary arterial and right ventricular pressures could be obtained. An indwelling needle was maintained in the brachial artery.

During the control period, three to four urine collections were usually obtained. Urine was collected at the end of each 10 to 15-minute period by washing out the bladder with $20 \mathrm{ml}$. of distilled water and evacuating the residual urine by displacement with air. Every twenty minutes arterial blood samples were obtained for the determinations of inulin, para-aminohippuric acid, chloride, sodium, potassium, and hematocrit. During the control period, one or two cardiac output determinations were made by the direct Fick method as well as measurements of the central vascular and peripheral arterial pressures as previously described (2). In 15 patients, after the control measurements had been obtained, cuffs on the thighs were inflated at slightly less than diastolic pressure (usually $70 \mathrm{~mm}$. $\mathrm{Hg}$ ). Venous congestion was maintained for 33 to 71 (average 55) minutes, during which time collections of urine were made at 10 to 20 minute intervals. In six other patients, venesections of 450 to 700 milliliters were accomplished over a period of 10 to 40 minutes. During, or shortly after, the phlebotomy, a urine collection was made for measurements of renal function which were designated as obtained "during phlebotomy." In most of the patients additional 


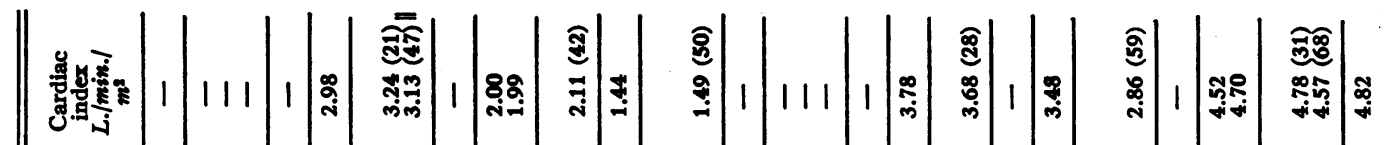

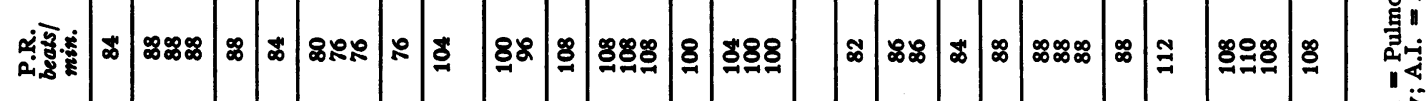

|

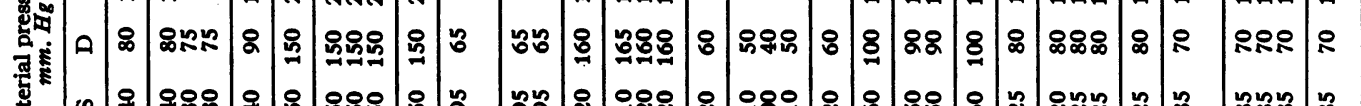

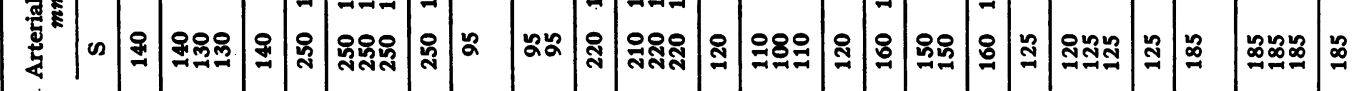

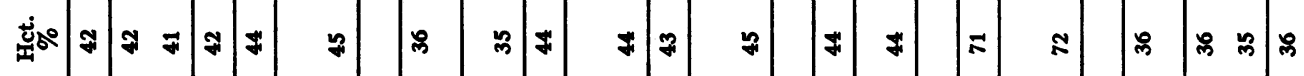
整重

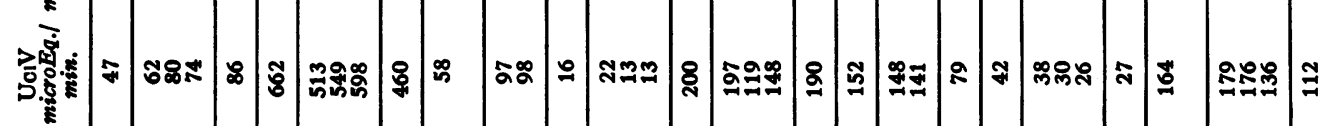

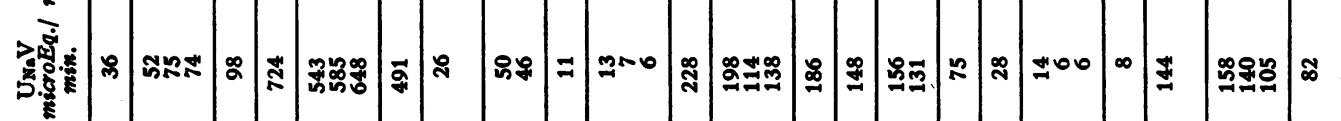

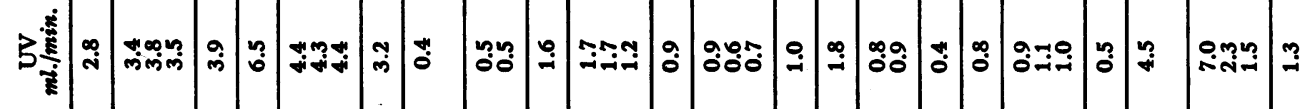

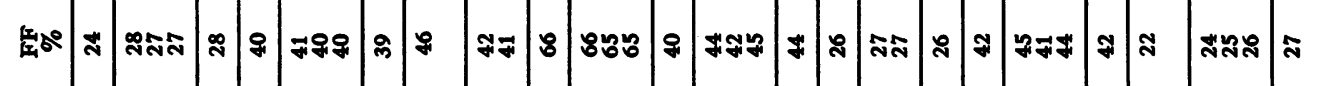

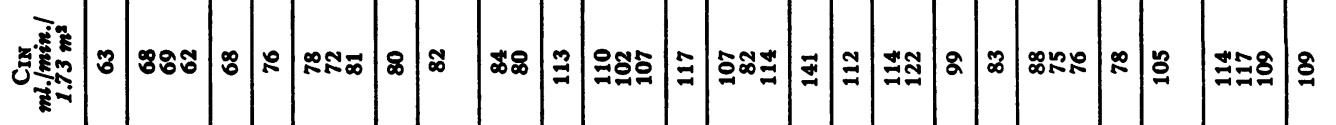

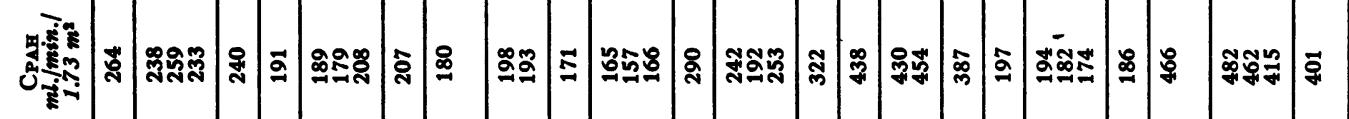

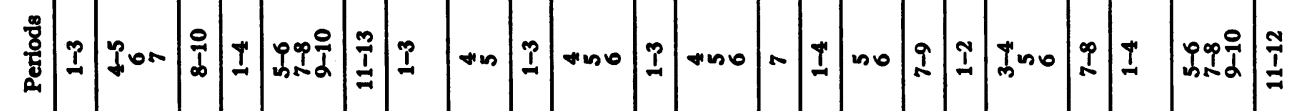

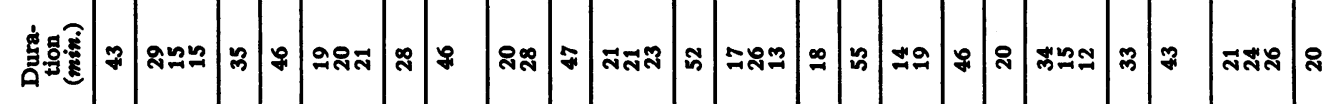

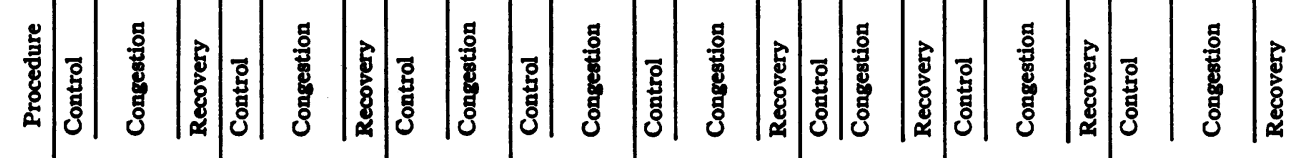

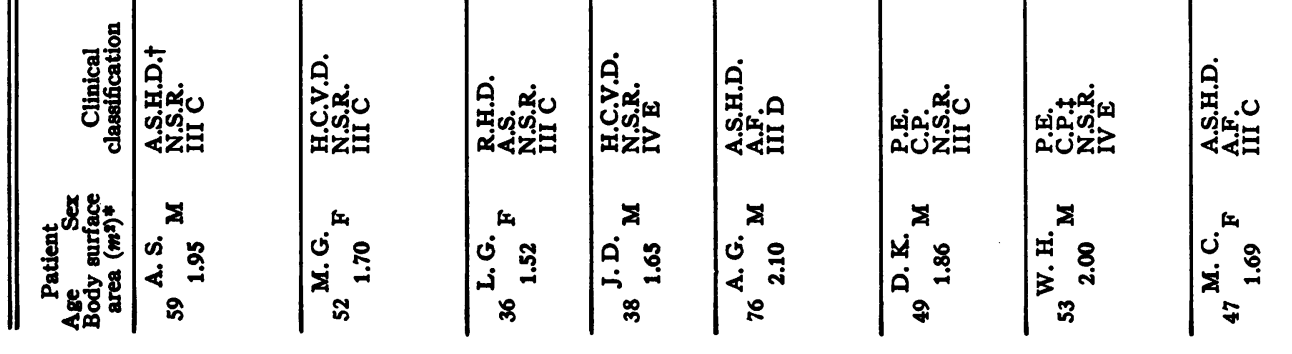
善蜜 
RENAL EFFECTS OF REDUCING BLOOD VOLUME IN CARDIACS

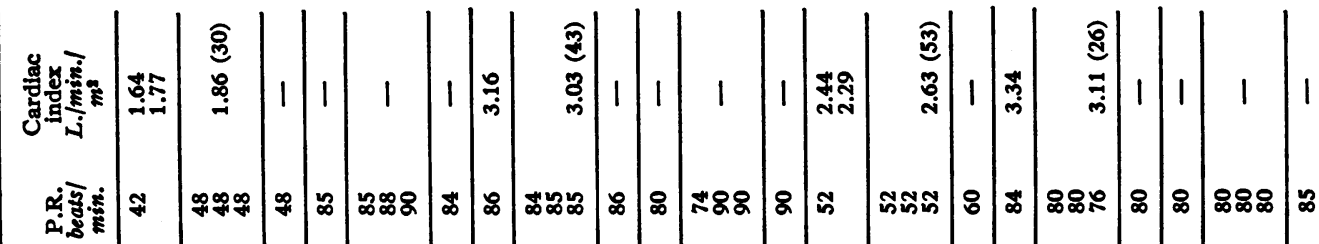

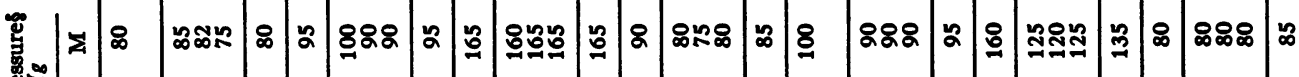
慧

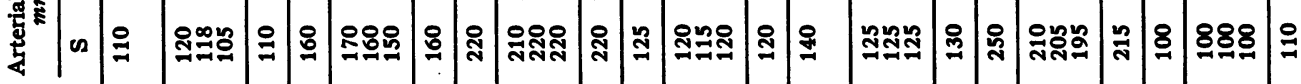

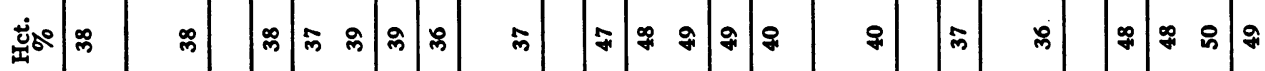

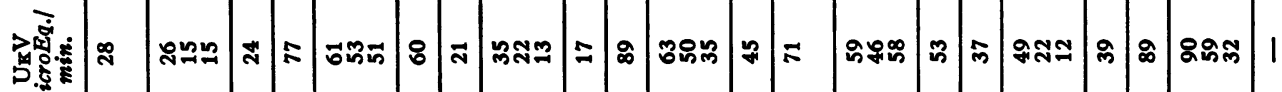

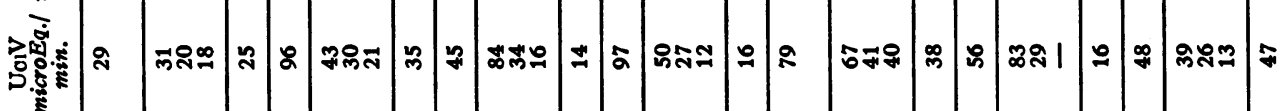

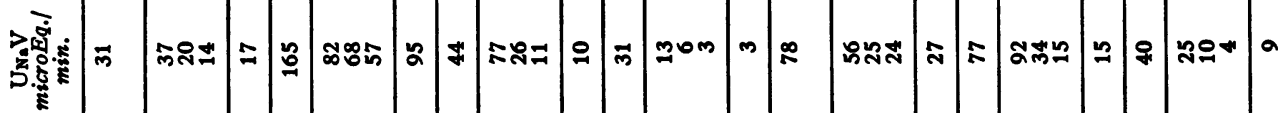
莫

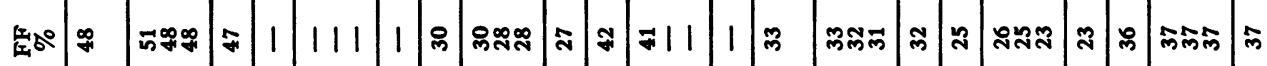

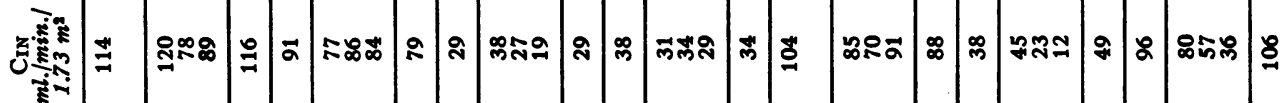

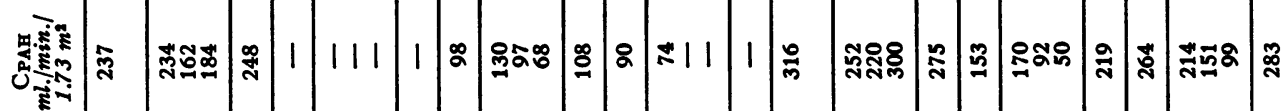

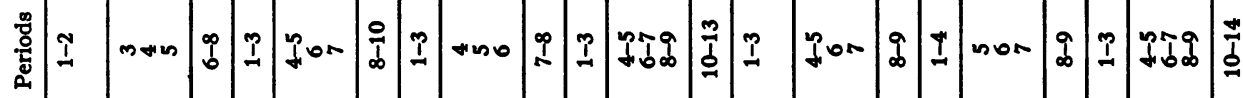

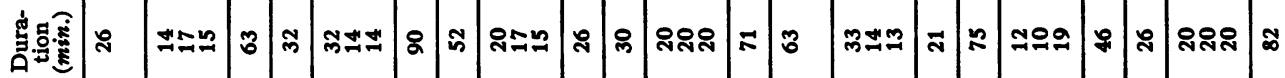

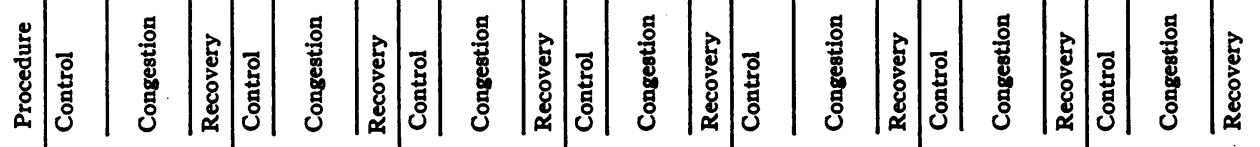
焉尊

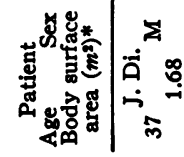
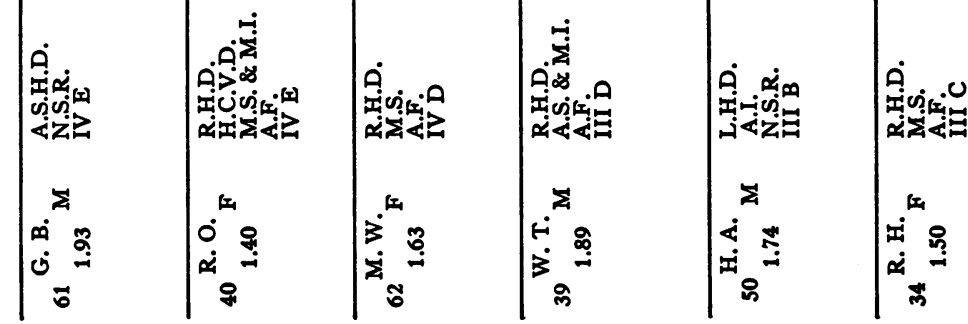


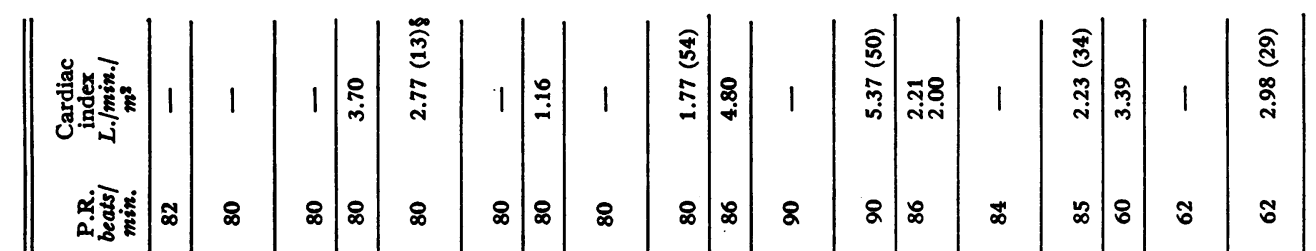

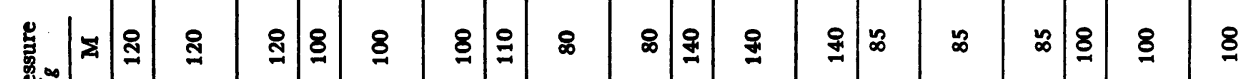
可 | 舟

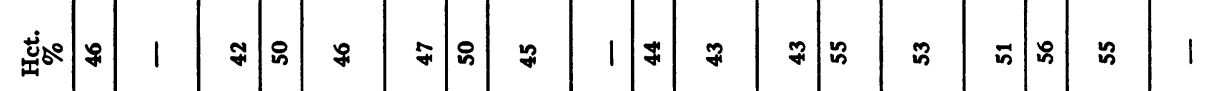

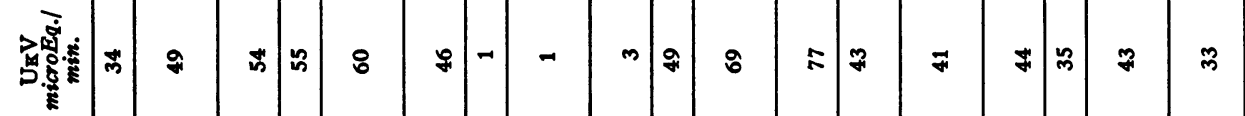

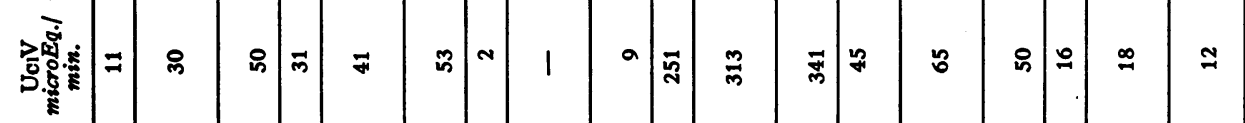

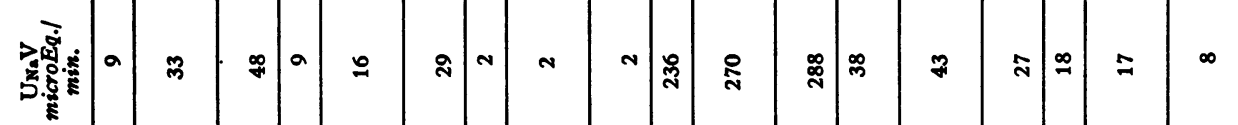
\#

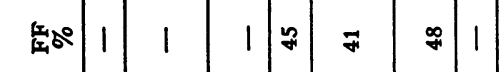

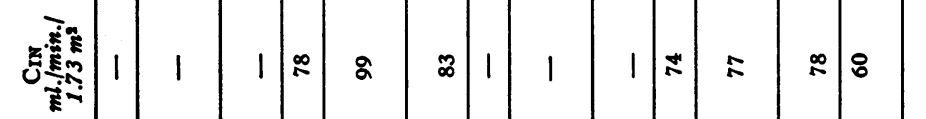

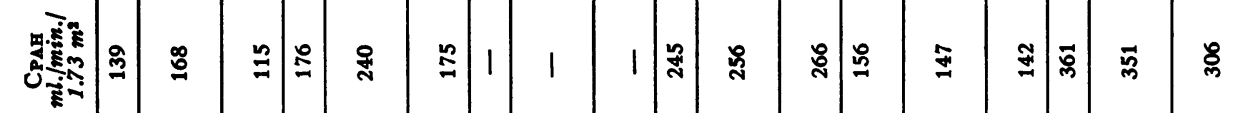

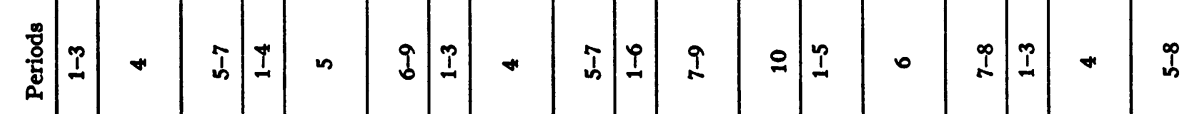

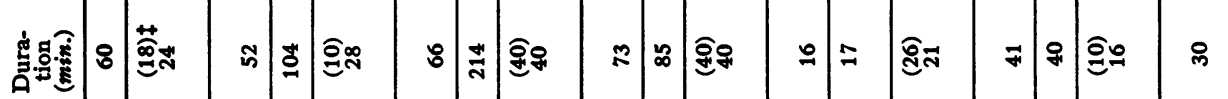

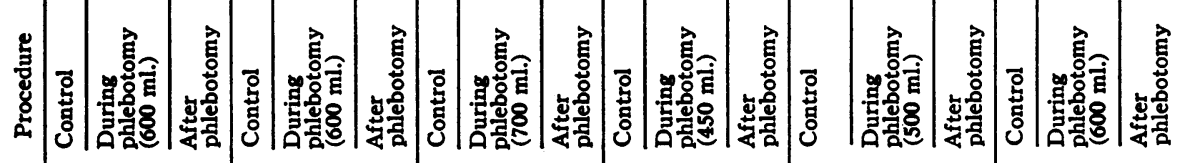

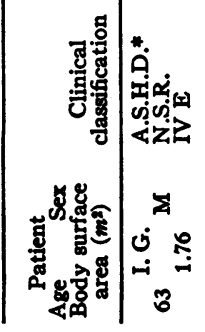
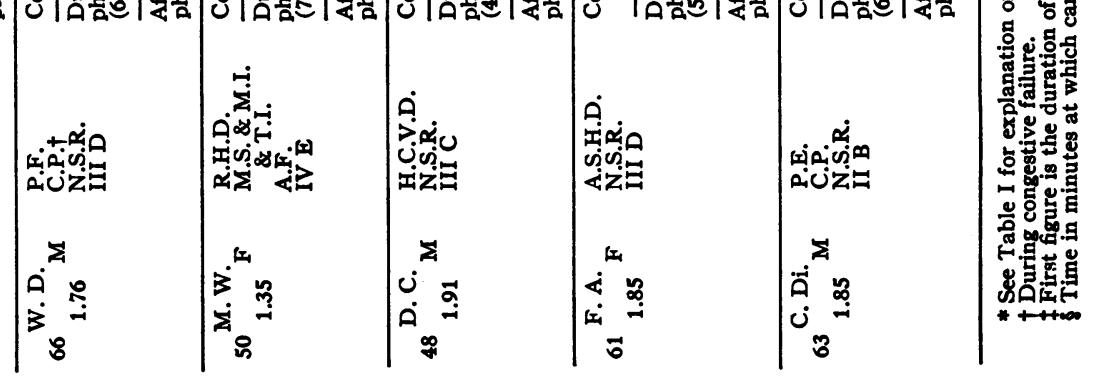
AS. \& 59-A.S.H.O. N.SR. IC

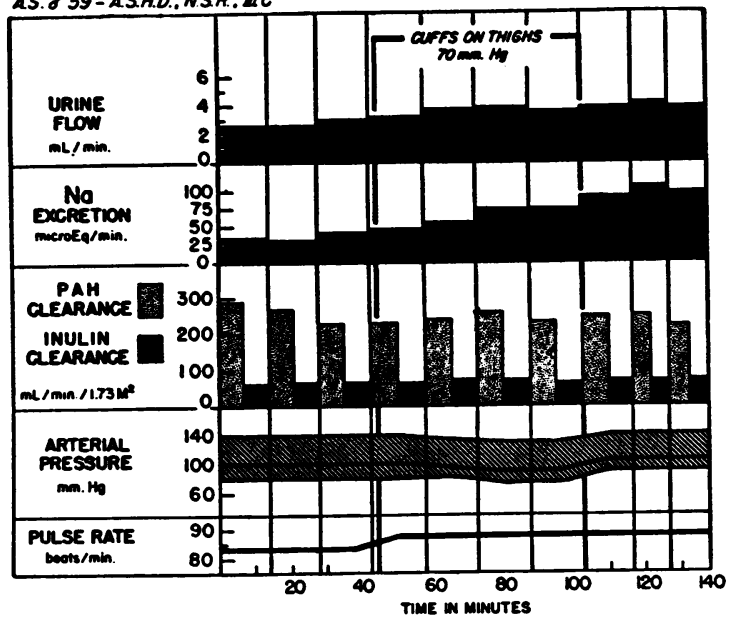

Fig. 1. Chart of Urine Flow, Sodium Excretion, PaH Clearance, Inulin Clearance, Arterial Pressure, and Pulse Rate in a Patient with Arteriosclerotic Heart Disease and Congestive FaIlure in Whom Venous Congesting Cuffs on the Thighs Were APPLIEd FOR 60 Minutes

Note the slight increase of urine flow, slight but progressive increase in the excretion of sodium, and the absence of significant change in the renal clearances or arterial pressure.

urine collections were made at 10 to 20 -minute intervals after the release of the venous congesting cuffs or completion of venesection. In ten patients, measurements of cardiac output and central vascular pressures were repeated after 7 to 68 minutes of continuous venous congestion of the legs. In five patients, similar measurements were made from 3 to 20 minutes after the completion of venesection. Because of the difficulty of the determination, frequent measurements of cardiac output were impossible. They had to be "spotted" at various intervals when they were considered to be most desirable as judged from the general clinical condition of the patient (Tables I and II). Arterial pressures on the other hand were taken continuously.

All pressures were measured with electromanometers ${ }^{8}$ and recorded by direct-writing oscillograph. Mean pressures were determined by electrical integration. Blood and urine concentrations of para-aminohippuric acid were measured by the method of Goldring and Chasis (3), and inulin was determined by the method of Schreiner (4) or Roe, Epstein, and Goldstein (5). Serum and urinary sodium and potassium were determined by the internal standard flame photometer (lithium standard). Serum and urinary chlorides were analyzed by the method of Wilson and Ball (6). The hematocrit was measured in Wintrobe tubes.

s Sanborn Company, Cambridge, Massachusetts.
RESULTS

\section{Urine flow and sodium excretion}

The responses to venous congestion of the legs are summarized in Table $I$, and those to phlebotomy in Table II. In both Tables the patients are listed in the approximate order of increasing degrees of antidiuretic response (see Discussion). Thus, at the top of Table I patients A. S., M. G., and L. G. had little or no fall in urine flow during venous congestion, and that two of them (A. S. and L. G.) had an increase in sodium excretion (Figure 1). Reading downward in Table I more definite antidiuretic responses are seen (Figure 2) and at the bottom are found the strong responses, usually seen in normal subjects, of patients W. T., H. A., and R. H., all of whom had definite decreases in both urine flow and sodium excretion during venous congestion of the limbs.

Table II is arranged similarly and demonstrates

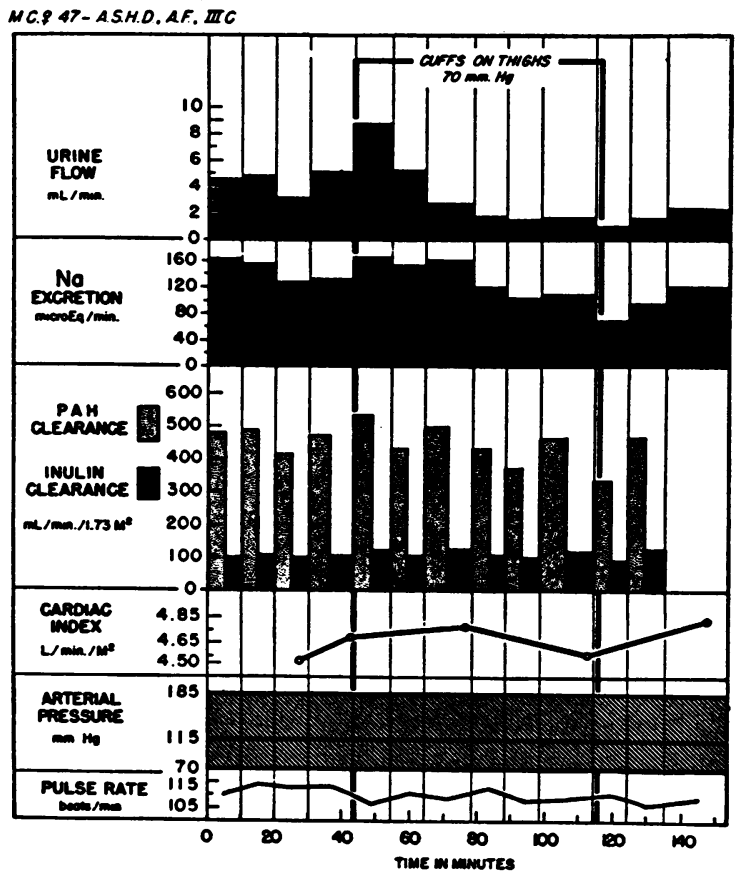

Fig. 2. Chart of an Experiment in a Patient with Arteriosclerotic Heart Disease and Congestive Failure Conducted Similarly to that Shown in Figure 1 Except that the Additional Measurement of Cardiac Output Was Made

Note the definite and progressive reductions in urine flow and the excretion of sodium, slight decreases in PAH clearance, and the insignificant changes in cardiac output and arterial pressure. 
that patients who had sizable venesections showed somewhat less marked reductions in urine flow than those who had definite antidiuretic responses to venous congestion of the extremities. None of the patients in this group had a reduction in the excretion of sodium (or chloride) during phlebotomy ; in fact, patients I. G., W. D., D. C. actually appeared to have increases in the rate of excretion of sodium. However, after the completion of the phlebotomy (when, of course, the blood volume was presumed to be most reduced), the excretion of sodium decreased in two patients ( $F$. A., C. Di.) while the renal plasma flow decreased slightly, along with the glomerular filtration rate (in patient F. A.).

\section{Renal hemodynamic responses}

Changes in renal plasma flow $\left(\mathrm{C}_{\mathrm{PAB}}\right)$ and glomerular filtration rate $\left(\mathrm{C}_{\mathrm{IN}}\right)$ during (and after) venous congestion ranged from none or slight in patients who had little or no antidiuretic response, to definite decreases in those who had a marked antidiuretic response. During phlebotomy the $\mathrm{C}_{\mathbf{P A B}}$ and $\mathrm{C}_{\mathrm{IN}}$ remained unchanged or increased slightly above the control values. As mentioned above, two patients (F. A., C. Di.) who showed the most striking antidiuresis after phlebotomy had decreases in $\mathrm{C}_{\mathbf{P A H}}$. Filtration fraction (FF) remained essentially unchanged in all subjects. Although the excretion of potassium showed no consistent alteration, in general it paralleled the changes in glomerular filtration rate.

\section{Cardiohemodynamic responses}

In this paper, only the changes in cardiac output and arterial pressure during venous congestion or after phlebotomy are presented. Right ventricular and pulmonary arterial pressures were measured simultaneously and have been presented separately (2). Suffice it to say here, these pressures decreased or remained the same, and in any case did not show any consistent correlation with changes in cardiac output or renal excretion.

As seen in the lower portions of Tables I and II in those patients showing definite decreases in urine flow and excretion of sodium during venous congestion or after phlebotomy, either a reduction or no change was observed in cardiac output, arterial pressure, or both. This was true regard- less of the control levels of cardiac output or arterial pressure, or of the type of congestive heart failure. In general, but not invariably, the more marked cardiohemodynamic changes were associated with the more marked renal excretory changes. In the upper portions of the Tables, on the other hand, those patients who had no decreases, or had increases in urine flow, in sodium excretion or both, had (with the exception of W. D.) no appreciable change or increases in cardiac output, arterial pressure or both. The hematocrit either did not change or increased slightly during venous congestion, but it decreased after phlebotomy.

\section{DISCUSSION}

Previous studies have indicated that the decreases in urine flow and sodium excretion occurring during venous congestion of the limbs of normotensive and compensated hypertensive subjects are consequences of a reduction in the effectively circulating blood volume (1). These responses do not appear if the reduction is offset by a large transfusion given simultaneously with the congestion of the limbs (7). Therefore, the responses appeared to be related to the homeostatic mechanisms tending to counteract the effects of a suboptimal effectively circulating blood volume. This view was supported by the observation that these responses were particularly pronounced and prolonged if a clinical state of collapse of the circulation occurred, with hypotension, anxiety, pallor, sweating, nausea, or faintness.

It was of considerable interest to examine what and where the stimuli may be that call forth these responses which occur quite regularly in normotensive and compensated hypertensive subjects. Cardiohemodynamic studies in such subjects indicate that congesting the limbs usually decreases the cardiac output without consistently causing measurable changes in systemic or pulmonary arterial pressure or right ventricular enddiastolic pressure (2). Any decrease in cardiac output during venous congestion therefore appeared usually to indicate a reduction in effectively circulating blood volume, which if it were not counteracted by vasomotor (and other homeostatic) adjustments would result in definite arterial hypotension, and indeed does so when the 
vasomotor reflexes are blocked by drugs (8). Therefore the hypothesis was accepted that the antidiuretic responses to venous congestion of the limbs are homeostatic reactions to suboptimal amounts of effectively circulating blood.

By extending the study to cardiac patients with congestive failure it was possible further to test this hypothesis. Thus it was found, as others have shown $(9,10)$, that certain patients in congestive failure have increases in cardiac output during venous congestion of the limbs, whereas other patients in failure, like normal subjects, may have decreases. Since both groups had similar or no changes in pulmonary arterial and right ventricular end-diastolic pressures, the question arose whether any connection existed between their cardiohemodynamic responses and their renal excretory responses. To make this comparison, it was necessary first to grade the renal excretory responses. This was done (in Tables I and II) on the basis of the following general considerations. The antidiuretic response was considered to be definite provided the control rate of urine flow was over $2 \mathrm{ml}$. per minute (and preferably over $3 \mathrm{ml}$. per min.) and if : 1 . A decrease in urine flow occurred to or below 25 per cent of the control rate and to or below $2 \mathrm{ml}$. per minute; 2 . A decrease in sodium excretion occurred to or below 75 per cent of the control rate.

A definite decrease in sodium excretion was considered a stronger response physiologically than a definite decrease in urine flow because reduced sodium excretion was never seen in normal subjects in the absence of a definite reduction in urine flow, whereas the reverse was seen not infrequently. Therefore, if only a moderate decrease of urine flow occurred (to 50 per cent of the control) the antidiuretic response was regarded as slight whereas if urine flow decreased to 10 per cent and sodium excretion to 50 per cent the response was regarded as strong. Only rarely was a slight response found to occur in a normal subject, and an increase in urine flow or sodium excretion or both was never seen in a normal subject or in a compensated hypertensive patient and would have been regarded as most unusual in this group.

One other factor in addition to the nature and degree of these responses was considered of importance in grading them. This was the per- sistence of the changes observed. Thus after collapse of the circulation, the responses not only were severe and included reductions in urine flow, sodium excretion, renal plasma flow and glomerular filtration rate but they persisted for some time after the stimulus and recovered in an order the reverse of that just listed, sometimes only after an hour.

Obviously from these considerations all gradations of renal excretory responses would be conceivably possible, from a definite antidiuresis to an actual diuresis of water and sodium. Indeed every gradation of response was seen in patients with congestive failure. Thus in Table I, patient A. S. (at the top) had an increase in the rates both of urine flow and of sodium excretion, while patients M. G. and L. G. had no change in either as defined above. Patient M. C. (in the middle of the table) had a definite reduction in urine flow and a moderate decrease in sodium excretion during venous congestion. Finally at the bottom, patients W. T., H. A., and R. H. had definite decreases in both urine flow and sodium excretion.

As already stated the degree of the renal functional changes appeared to be roughly correlated with the degree of the cardiohemodynamic responses to these stimuli. Thus, patients who had a definite antidiuretic response (in the lower part of the Tables), like normal subjects and compensated hypertensive patients, usually, but not invariably, had decreases in cardiac output, arterial pressure or both during venous congestion of the limbs or after phlebotomy. In sharp contrast, patients who had no decrease or had an increase in urine flow or sodium excretion (upper part of the Tables) either had no significant change or an increase in cardiac output and arterial pressure.

There were no consistent qualitative differences in the responses of the patients whose effectively circulating blood volumes were reduced by venous congestion of the limbs and of those who had venesections. However, there were quantitative differences in that venous congestion more frequently caused measurable decreases in cardiac output and definite decreases in the renal excretion of water and salt. Thus, at least half of the patients in failure who had venous congestion of the limbs had definite antidiuretic responses while no more than a third of those who had phlebotomy had such responses. 
These quantitative differences in the effects of venous congestion and of phlebotomy may be related to the quantitative differences between the amount of blood removed from active circulation in each case. It is estimated that venous congestion, as employed in these experiments, pools somewhat more than $1,000 \mathrm{ml}$. of blood in the limbs whereas the largest phlebotomy performed was $700 \mathrm{ml}$. It seems logical, and it has been repeatedly observed clinically, that in patients with severe congestive failure, a moderate reduction in effective circulating blood volume may result in subjective relief and evidences of circulatory improvement, but that too great a reduction in volume may cause rapid deterioration of the circulation even to the point of circulatory collapse. Thus there presumably is an optimal effectively circulating blood volume for each individual patient, deviations from which, either above or below the optimum, would bring unfavorable consequences.

This assumption is compatible with the observations made in the present study. It was repeatedly observed that when arterial pressure fell or became unusually variable, when the arterial wave fronts assumed a peaked "collapse" form with a low or absent dicrotic notch and a flat diastolic run-off, or even more important, when the patient became anxious, pale, sweaty, nauseous, or faint definite antidiuresis and reduction in sodium excretion would follow. Occasionally collapse occurred (as in patient J. Di.) even though cardiac output was found not to be decreased when it was measured. For these reasons, reductions in both arterial pressure and cardiac output were regarded as important, but not the only important, objective signs of imminent collapse. Pulse rate acceleration in these patients with congestive failure was a less reliable sign of inadequate circulating blood volume than in normotensive or compensated hypertensive subjects. Presumably this was because of digitalization of the patients, and also because of the associated arrhythmias present in many of them.

It is clear from the above considerations that we have come to regard a clinical state of imminent circulatory collapse as the important stimulus to the renal excretory changes of reduced urine flow, reduced sodium excretion, and (at least initially) decreased renal plasma flow, and glomerular filtration rate. In general this state may be signaled by reductions in cardiac output, arterial pressure or both. It certainly is not invariably accompanied by a reduction in right ventricular or pulmonary arterial pressure. Circulatory collapse may be said to be imminent, or possible, whenever there is a suboptimal, hypovolemic, and hypokinetic state of the circulation. If this is a reasonable concept, it may account for the fact that the only group of patients in congestive failure who showed a poor correlation between reductions in cardiac output and reductions in water and salt excretion during the hypovolemic procedure employed were those with cor pulmonale and so-called "high output" failure. Thus patient $W . H$. during venous congestion and patient W. D. after phlebotomy had sizable reductions in cardiac output, arterial pressure or both, but only a relatively small decrease in urine flow or sodium excretion. It seems possible that these patients actually had a more "normal" circulation during the hypovolemic procedure than before. One such patient, C. Di., however, did show the usual antidiuretic response when the cardiac output and arterial pressure were reduced.

The explanation just offered, namely that a suboptimal, hypovolemic, hypokinetic state of the circulation is the effective stimulus to the antidiuretic resporise, is also compatible with the observation that closing a large, long-established arteriovenous shunt usually causes an increase in sodium and water excretion, whereas opening a new AV shunt in dogs generally causes a decrease in water and salt excretion (11). In these latter experiments the changes in right cardiac and pulmonary arterial pressures are just the opposite to those found in hypovolemic experiments, but the systemic arterial pressures, and indeed the danger of circulatory collapse, and the renal excretory responses are similar. Although it is true that the cardiac output increases in the shunt-opening experiments, and decreases in the blood-volume-reducing experiments, relative to demand it may be presumed to be suboptimal in both. Therefore, no single cardiohemodynamic measurement in itself can be taken as uniformly indicative of a suboptimal circulation. Only when the supply of effectively circulating blood relative to demand is adequate can the circulation be said to be optimal. A suboptimal state of the circulation undoubtedly 
sets in motion a battery of compensating homeostatic mechanisms. One of these appears to be a relative decrease in water and salt excretion.

\section{SUMMARY}

1. In response to venous congestion of the legs or to a phlebotomy of 450 to $700 \mathrm{ml}$. of blood, patients with congestive heart failure may or may not have the decreases in water and salt excretion which normally occur in individuals without heart failure.

2. Simultaneous cardiohemodynamic measurements suggest that decreases in sodium and water excretion are more apt to occur after venous congestion or bleeding when there is a decrease in cardiac output or peripheral arterial pressure or clinical signs of imminent circulatory collapse. Increases in sodium and water excretion are more apt to occur after the same procedures if there is an increase in cardiac output or peripheral arterial pressure.

3. No apparent relationship was noted between the renal responses and changes in pulmonary arterial and right ventricular pressures.

4. The observed decreases in renal function after venous congestion of the legs or phlebotomy may be regarded as homeostatic responses to a suboptimal effectively circulating blood volume.

\section{REFERENCES}

1. Wilkins, R. W., Tinsley, C. M., Culbertson, J. W., Burrows, B. A., Judson, W. E., and Burnett, C. H., The effects of venous congestion of the limbs upon renal clearances and the excretion of water and salt. I. Studies in normal subjects and in hypertensive patients before and after splanchnicectomy. J. Clin. Invest., 1953, 32, 1101.
2. Judson, W. E., Hollander, W., Hatcher, J. D., Halperin, M. H., and Friedman, I. H., The cardiohemodynamic effects of venous congestion of the legs or of phlebotomy in patients with and without congestive heart failure. J. Clin. Invest., 1955, 34, 614.

3. Goldring, W., and Chasis, H., Hypertension and Hypertensive Disease. New York, The Commonwealth Fund, 1944.

4. Schreiner, G. E., Determination of inulin by means of resorcinol. Proc. Soc. Exper. Biol. \& Med., 1950, 74, 117.

5. Roe, J. H., Epstein, J. H., and Goldstein, N. P., A photometric method for the determination of inulin in plasma and urine. J. Biol. Chem., 1949, 178, 839.

6. Wilson, D. W., and Ball, E. G., A study of the estimation of chloride in blood and serum. J. Biol. Chem., 1928, 79, 221.

7. Hatcher, J. D., Judson, W. E., Emerson, C. P., and Wilkins, R. W., The effects of venous congestion of the limbs upon renal clearances and the excretion of water and salt. IV. Prevention in normal subjects by a large transfusion. To be published.

8. Freis, E. D., Stanton, J. R., Finnerty, F. A., Jr., Schnaper, H. W., Johnson, R. L., Rath, C. E., and Wilkins, R. W., The collapse produced by venous congestion of the extremities or by venesection following certain hypotensive agents. J. Clin. Invest., 1951, 30, 435.

9. Warren, J. V., Brannon, E. S., Stead, E. A., Jr., and Merrill, A. J., The effect of venesection and the pooling of blood in the extremities on the atrial pressure and cardiac output in normal subjects with observations on acute circulatory collapse in three instances. J. Clin. Invest., 1945, 24, 337.

10. Howarth, S., McMichael, J., and Sharpey-Schafer, E. P., Effects of venesection in low output heart failure. Clin. Sc., 1946, 6, 41.

11. Epstein, F. H., Post, R. S., and McDowell, M., The effect of an arteriovenous fistula on renal hemodynamics and electrolyte excretion. J. Clin. Invest., 1953, 32, 233.

\section{SPECIAL NOTICE TO SUBSCRIBERS}

Post Offices will no longer forward the Journal when you move.

Please notify The Journal of Clinical Investigation, Business Office, 622 West 168th Street, New York 32, N. Y. at once when you have a change of address, and do not omit the zone number if there is one. 